\title{
Differences Between Perimenstrual Migraine Attacks and Migraine Attacks at Other Times of the Cycle
}

E. Anne MacGregor, MB, BS, MSc, MD, FFSRH

Neurology $^{\circledR}$ 2021;97:e1753-e1756. doi:10.1212/WNL.0000000000012741

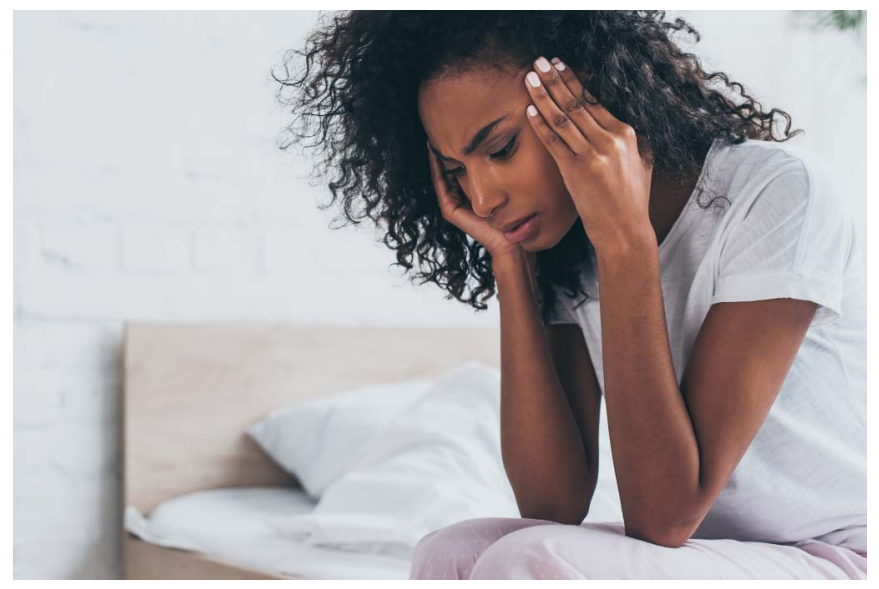

Related Article

Comparing

Perimenstrual and

Nonperimenstrual

Migraine Attacks

Using an e-Diary

http://dx.doi.org/10.1212/ WNL.0000000000012723

\section{What Was Studied and Why Is It Important?}

Menstrual migraine is an important condition in which women experience regular migraine around the time of their period. This is defined as migraine attacks that occur within a 5-day window starting 2 days before the first day of menstruation through to the third day of bleeding. ${ }^{1}$ Recognizing menstrual migraine is important for management. Research has shown that migraine attacks that happen near the menstrual period are more severe, last longer, and are less responsive to treatment than attacks that happen at other times. ${ }^{2}$ Little is known about whether perimenstrual migraine attacks are more troublesome for women who have not received a specific diagnosis of menstrual migraine. The study by van Casteren et al. ${ }^{3}$ compared perimenstrual migraine attacks with migraine attacks occurring at other times of the cycle. This study examines whether differences between perimenstrual and nonperimenstrual attacks exist in women with and without a specific diagnosis of menstrual migraine.

\section{How Was the Study Done?}

The authors recruited Dutch women diagnosed with migraine and had them track symptoms in a diary for 105 days. The women were asked daily to describe any headache in the preceding 24 hours. They recorded the characteristics of the headache and associated symptoms such as light or sound sensitivity, nausea, and vomiting. They were also asked to note any medication they had taken, as well as whether they were menstruating. Women not using hormonal contraception were asked additional questions about their premenstrual symptoms. 


\section{What Were the Main Study Findings?}

Five hundred women completed the diary for at least 1 month. Compared to attacks at other times of the menstrual cycle, perimenstrual attacks were more severe. They lasted longer, required more medication treatment, were more likely to recur, and included more sensitivity to light and sound. Women also reported that they were less able to cope with the pain of perimenstrual migraine attacks.

The researchers looked at women both with and without a diagnosis of menstrual migraine. About half of the participants who completed the study were diagnosed with menstrual migraine. Only in women with menstrual migraine were perimenstrual attacks different. In this group, headaches lasted longer, required more medication to treat, and caused more sensitivity to light and sound. Women diagnosed with menstrual migraine were no more likely to experience premenstrual syndrome than women without menstrual migraine.

Women using hormonal contraception with a monthly withdrawal bleed were also identified as experiencing longer and more severe perimenstrual migraine attacks.

\section{What Does This Mean for Women With Migraine?}

These results highlight the need for better management of perimenstrual attacks in all menstruating women.
However, the differences between perimenstrual and nonperimenstrual attacks were most pronounced in women diagnosed with menstrual migraine and in women using combined hormonal contraception. This shows that an accurate diagnosis of menstrual migraine remains important for management of this type of migraine. As shown in this study, this diagnosis can be easily reached by instructing a woman experiencing migraine to keep a diary of migraine days and menstruation days over at least 3 consecutive menstrual cycles. ${ }^{4}$

\section{What Isn't Known Yet?}

To date, there is only limited research about specific treatments for perimenstrual migraine, even though these attacks often cause significant disability. For women who are already taking combined hormonal contraception, the simplest strategy is for them to take their contraception continuously, without a break for a withdrawal bleed. This allows them to avoid the menstrual trigger that causes migraine. ${ }^{2}$ Treatment options for women who do not use or need hormonal contraception are limited, however. ${ }^{2}$ The results of this study highlight the importance of future research in understanding the underlying causes of menstrual migraine attacks. Furthermore, all migraine treatment studies should separately assess the effects of treatment on perimenstrual and nonperimenstrual attacks in women with and without menstrual migraine. 


\section{About Migraine}

\section{What Is Migraine?}

In general, migraine is a recurring headache that typically lasts between a few hours and a few days. The pain is often on just one side of the head, but in some people, it can occur all over the head. Migraine symptoms are often made worse by movement. A migraine attack is usually accompanied by nausea, and sometimes vomiting, as well as sensitivity to light and sound. While treatment allows some people to continue their usual activities during an attack, other people are completely disabled by their migraine attacks and must lie down in a quiet, darkened room until the symptoms go away. Painkillers and migraine-specific medications such as triptans and ditans are sufficient to reduce the severity of symptoms for most people who experience migraine. If necessary, additional daily preventive treatment can reduce the likelihood of attacks developing. Migraine without aura is the most common type of migraine. It makes up $70 \%-80 \%$ of attacks. About $30 \%$ of attacks are preceded by a warning sign known as an aura. The aura is typically visual, often described as bright zigzags that gradually expand across half of a person's field of vision over a period of about 20-30 minutes, and usually resolves before the headache starts. It is possible for individuals to experience more than 1 migraine type.

\section{How Common Is Migraine?}

Migraine affects 1 in 7 adults worldwide. It is 2-3 times more common in women than in men. It is the leading cause of disability in women of reproductive age. ${ }^{2}$

\section{What Is Menstrual Migraine and How Is It Diagnosed?}

Many women notice a link between migraine and their menstrual periods. Studies have shown that migraine is more likely to occur during a 5-day perimenstrual window that starts 2 days before a menstrual period and continues through the first 3 days of bleeding. ${ }^{2}$ The International Headache Society recognizes 2 types of menstrual migraine. The first is menstrually related migraine, in which migraine attacks regularly occur on or between day -2 and +3 of menstruation. Additional attacks of migraine may occur at other times of the cycle. The second type is pure menstrual migraine, which is migraine that occurs only on or between day -2 and +3 of the menstrual period. That is, no attacks occur at any other time of the cycle. ${ }^{1}$ To confirm the diagnosis, there must be perimenstrual migraine attacks in at least 2 of 3 menstrual cycles. In women diagnosed with menstrual migraine, perimenstrual attacks typically last longer, are less responsive to treatment, and are more severe and disabling compared to attacks at other times of the menstrual cycle. ${ }^{2}$

\section{How Common Is Menstrual Migraine?}

Although up to $60 \%$ of women with migraine report selfdiagnosed menstrual migraine, studies using strict criteria indicate that $18 \%-25 \%$ of women with migraine have menstrual migraine without aura. ${ }^{2}$ Menstrual migraine is most likely to affect women during perimenopause, when menstrual cycle hormones become more erratic.

\section{What Causes Menstrual Migraine?}

Research has shown that some women with migraine are more susceptible to attacks when estrogen levels fall. This occurs during the natural menstrual cycle a few days before menstruation, triggering migraine. This estrogenwithdrawal trigger is also thought to cause migraine attacks during breaks in the use of hormonal contraception. Another potential trigger is hormones called prostaglandins, which are released during menstruation and are often associated with heavy, painful periods. ${ }^{2}$

\section{What Is the Treatment for Menstrual Migraine?}

Management of perimenstrual migraine attacks is the same as the management of nonmenstrual attacks. Many countries have specific guidelines for migraine management that provide information regarding treatment options. It is important to treat early with an adequate dose and to repeat if symptoms recur. To avoid headache from medication overuse, symptom treatment should be kept to 9 days or fewer per month on average. It does not matter if a single dose or multiple doses are taken in any 1 day, as it is the number of days treated that is relevant. If symptom treatment alone does not suffice, preventive treatment can be considered. Lifestyle strategies, as well as identification and reduction of potential migraine triggers, are parts of prevention. Menstrual disorders such as heavy or painful periods should be managed as well, as such treatment can also prevent menstrual migraine. There are a few options for targeted perimenstrual prevention starting a few days before the expected start of a perimenstrual attack and continued for several days. In migraine without aura, women using combined hormonal contraception can take the pill continuously without a break. Alternatively, they can shorten the number of days or frequency of the hormone breaks. Another option might be hormonal contraception that uses only progesterone and no estrogen. 


\section{For More Information}

\section{Brain \& Life}

brainandlife.org

\section{American Migraine Foundation} americanmigrainefoundation.org

\section{National Headache Foundation}

headaches.org

\section{Migraine World Summit}

migraineworldsummit.com

\section{References}

1. Headache Classification Committee of the International Headache Society (IHS). The International Classification of Headache Disorders, 3rd edition. Cephalalgia. 2018;38: $1-211$.

2. Vetvik K, MacGregor EA. Menstrual migraine: a distinct disorder needing greater recognition. Lancet Neurol. 2021; 20:304-315.

3. van Casteren DS, Verhagen IE, van der Arend $B W H$, van Zwet EW, MassenVanDenBrink A, Terwindt GM. Comparing perimenstrual and nonperimenstrual migraine attacks using an e-diary. Neurology. 2021;97(17):e1661-e1671.

4. Steiner TJ, Stovner LJ, Jensen R, Uluduz D, Katsarava Z; on behalf of Lifting The Burden: the Global Campaign against Headache. Migraine remains second among the world's causes of disability, and first among young women: findings from GBD2019. J Headache Pain. 2020;21:137. 


\title{
Neurology
}

\author{
Differences Between Perimenstrual Migraine Attacks and Migraine Attacks at Other \\ Times of the Cycle \\ E. Anne MacGregor \\ Neurology 2021;97; e1753-e1756 \\ DOI 10.1212/WNL.0000000000012741
}

This information is current as of October 25, 2021

\section{Updated Information \& Services}

References

Subspecialty Collections

Permissions \& Licensing

Reprints including high resolution figures, can be found at: http://n.neurology.org/content/97/17/e1753.full

This article cites 4 articles, 1 of which you can access for free at: http://n.neurology.org/content/97/17/e1753.full\#ref-list-1

This article, along with others on similar topics, appears in the following collection(s):

Autonomic diseases

http://n.neurology.org/cgi/collection/autonomic_diseases

Information about reproducing this article in parts (figures,tables) or in its entirety can be found online at:

http://www.neurology.org/about/about_the_journal\#permissions

Information about ordering reprints can be found online:

http://n.neurology.org/subscribers/advertise

Neurology ${ }^{\circledR}$ is the official journal of the American Academy of Neurology. Published continuously since 1951 , it is now a weekly with 48 issues per year. Copyright @ 2021 American Academy of Neurology. All rights reserved. Print ISSN: 0028-3878. Online ISSN: 1526-632X.

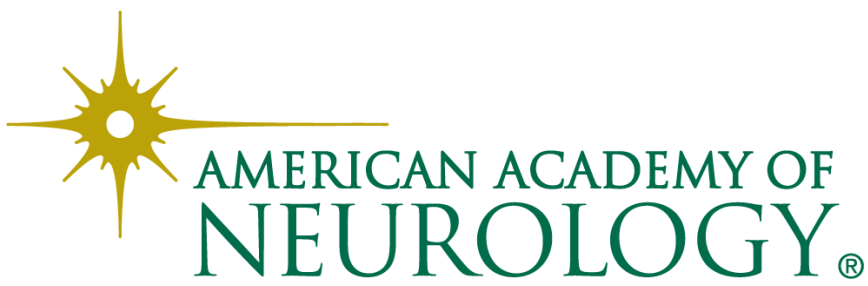

